\title{
Helicobacter Pylori Strains Isolated from Iraqi Subjects with Gastritis, Peptic Ulcer, and Carcinoma of Stomach Genetic Sequences: A New Variants
}

\author{
Abdulghani Mohamed Alsamarai ${ }^{*}$, Fatima Thegeal Moutar Alsaadi ${ }^{2}$, Farooq Ibrahim Mohamed ${ }^{3}$, Amina Hamed \\ Ahmed Alobaidii ${ }^{4}$ and Mohamed Baquer Alhili ${ }^{5}$ \\ Aalborg Academy of Science, Europe \\ Tikrit University College of Science, Europe
}

Al-Nahrain University College of Science, Iraq

Kirkuk University College of Veterinary Medicine, Iraq

AlQasim University College of Agriculture, Iraq

Submission: October 09, 2018; Published: November 21, 2018

"Corresponding author: Abdulghani Mohamed Alsamarai, Tikrit University College of Medicine, Tikrit Aalborg Academy of Science, Denmark, Europe

\begin{abstract}
Background: Genetic variations of the infectious agents play an important role on the influence of natural disease severity, response to treatment and morbidity.

Aim: To clarify if there are genetic variations in H. pylori clinical isolates from cases with gastritis, peptic ulcer and carcinoma of stomach.

Materials and Methods: Eight PCR product sample were sent for sequence analysis of H.pylori isolated from biopsy of stomach and $20 \mu \mathrm{l}$ (10pmol) from the Forward primer sequence is 5' -GGTTCAAATCGGCTCACACT-3' Reverse primer sequence is 5' ${ }^{\prime}$-CTCCTTAATTGTTTTTACATAG-3' They are made by primer 3PLUS software. The result of the sequence analysis was analyzed by blastn in the National Centre for Biotechnology Information (NCBI) and many software used to detect polymorphism in H. pylori.

Results: The present study H.pylori isolates were separated on the phylogenetic tree and belong to a population cluster different from previously reported H.pylori sequences. H.pylori variant 1 which was isolated from Iraqi patients with gastric cancer was most closely to strain Helicobacter pylori R037c isolated in Canada. While variants 2 and 3, which were isolated from peptic ulcer and variant 4, which was isolated from patient with gastritis were more closely to Helicobacter pylori 26695 isolated from patient with gastritis in UK. The present study data suggest that sub lineages evolution within the Helicobacter pylori species may be associated with the development of less or more pathogenic potential. In addition, the relation of the 4 variants to the American [Hp R037c] and European [Hp 26695] suggest that these variants diverged from American and European lineage ancestors as reported previously for other geographical areas. This study is the first one in Iraq that sequenced H.pylori isolates from patients with gastritis, peptic ulcer and gastric cancer and the gene diversity of the bacteria may be used as biomarker that may be used for follow up and prognosis in the above disease for prevention of development of cancer. Therefore, called GhaFa.1. Iraq for first isolate, GhaFa.2. Iraq for second isolate, GhaFa.3. Iraq for third isolate and GhaFa.4. Iraq for fourth isolate.
\end{abstract}

Conclusion: This study indicated that genetic variation in H. pylori was correlated to gastritis severity and was more in gastric cancer cases as compared to gastritis and peptic ulcer.

Keywords: H. pylori; Gastritis; Peptic ulcer; Carcinoma of stomach; Genetic variation; Sequencing

Abbreviations: NCBI: National Center for Biotechnology Information; PCR: Polymerase Chain Reaction; SNP: Single Nucleotide Polymorphism

\section{Introduction}

H. pylori infections are worldwide and affected many systems beyond the stomach [1]. However, the disease prevalence varied between different studies [2]. The infection was with a range of $28.3 \%$ to $100 \%$ in general population and it was more in subjects with gastritis and gastric carcinoma [2]. H. pylori infections was linked with gastric carcinoma [3], however, not all $\mathrm{H}$. pylori infected individuals will develop carcinoma of the stomach. Thus, development of gastric carcinoma and its association with H. pylori infections may interfere with risk factors which lead to potentiate cancer in certain subjects and not the others 
$[3,4]$. Previous studies reported abnormality in biomarkers in individuals with gastritis, peptic ulcer and gastric carcinoma, and the abnormality was more prominent in subject with cancer of stomach $[5,6]$.

Genetic variations of the infectious agents play an important role on the influence of natural disease severity, response to treatment and morbidity $[7,8]$. Thus, this study was conducted to clarify if there are genetic variations in H. pylori clinical isolates from cases with gastritis, peptic ulcer and carcinoma of stomach.

\section{Materials and Methods}

Eight PCR product sample were sent for sequence analysis of H.pylori isolated from biopsy of stomach and $20 \mu \mathrm{l}(10 \mathrm{pmol})$ from the Forward primer sequence is $5^{\prime}$-GGTTCAAATCGGCTCACACT- $3^{\prime}$ Reverse primer sequence is $5^{\prime}$-CTCCTTAATTGTTTTTACATAG-3' they are made by primer 3PLUS software. The result of the sequence analysis was analyzed by blastn in the National Centre for Biotechnology Information (NCBI). Online at (http:// www.ncbi.nlm.nil.gov) and many software used to detect polymorphism in H. pylori.

\section{Results and Discussion}

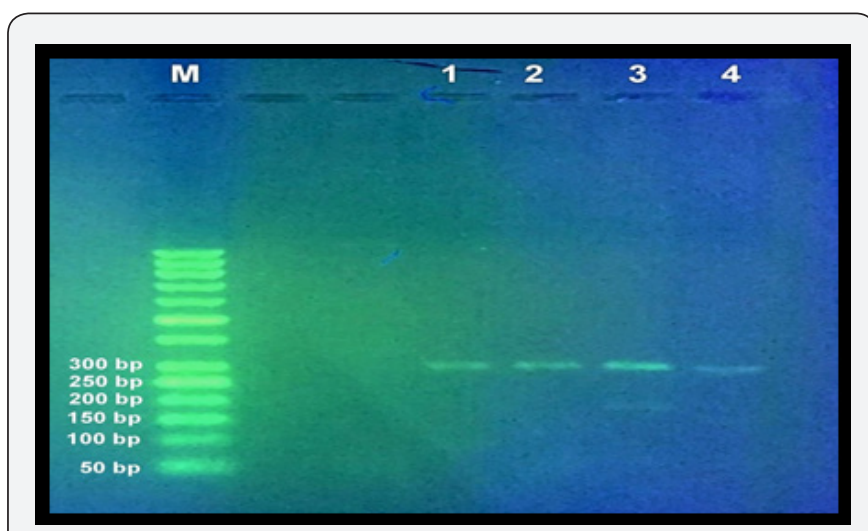

Figure 1a: PCR product the band size $301 \mathrm{bp}$. The product was electrophoresis on $2 \%$ agarose at 5 volt/cm2. $1 \times$ TBE buffer for 1:30 hours. N: DNA ladder (50), lane (1-6) PCR product of band size $301 \mathrm{bp}$, visualized under U.V light.

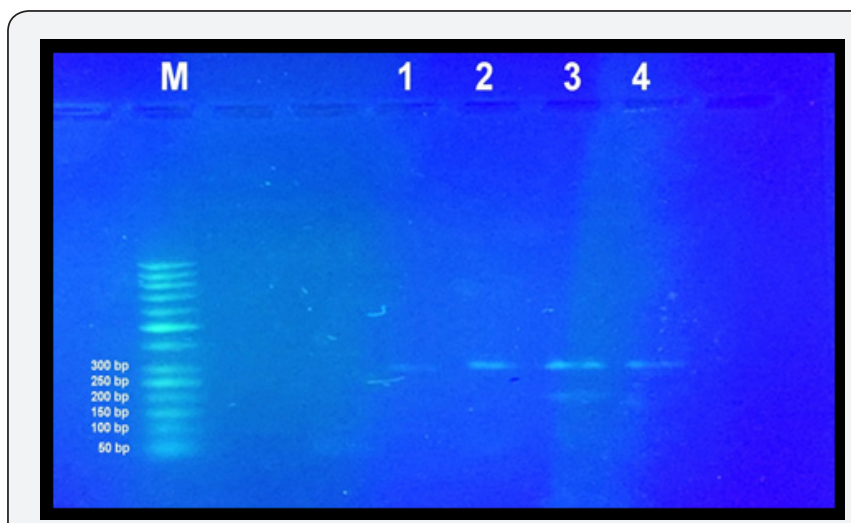

Figure 1b: PCR product the band size $301 \mathrm{bp}$. The product was electrophoresis on $2 \%$ agarose at 5 volt $/ \mathrm{cm} 2$. $1 \times$ TBE buffer for 1:30 hours. N: DNA ladder (50), lane (1-6) PCR product of band size $301 \mathrm{bp}$, visualized under U.V light.

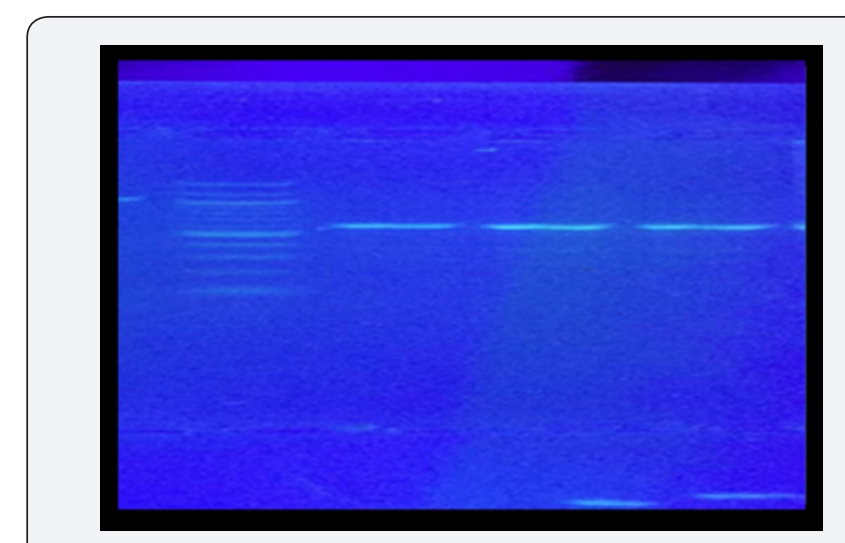

Figure 1c: PCR product the band size $301 \mathrm{bp}$. The product was electrophoresis on $2 \%$ agarose at 5 volt/cm2. $1 \times$ TBE buffer for 1:30 hours. N: DNA ladder (50), lane (1-6) PCR product of band size $301 \mathrm{bp}$, visualized under U.V light.

The result shown in Figure $1 \mathrm{~A}-\mathrm{C}$ indicated that a yield of single band of the desired product with a molecular weight of $301 \mathrm{bp}$ for urease gene of $\mathrm{H}$. pylori was obtained from 8 samples. Eight PCR product sample were sent for sequence analysis of H.pylori isolated from biopsy of stomach and $20 \mu \mathrm{l}(10 \mathrm{pmol})$ from the Forward primer sequence is $5^{\prime}$-GGTTCAAATCGGCTCACACT- $3^{\prime}$ Reverse primer sequence is $5^{\prime}$-CTCCTTAATTGTTTTTACATAG-3'

They are made by primer 3PLUS software. The result of the sequence analysis was analyzed by blastn in the National Centre for Biotechnology Information (NCBI). Online at (http:// www.ncbi.nlm.nil.gov) and many software used to detect polymorphism in H. pylori found variation include Transversion (refers to the substitution of a (two ring) purine or a (one ring) pyrimidine and transition a (point mutation) that changes a purine to another purine or pyrimidine to another pyrimidine

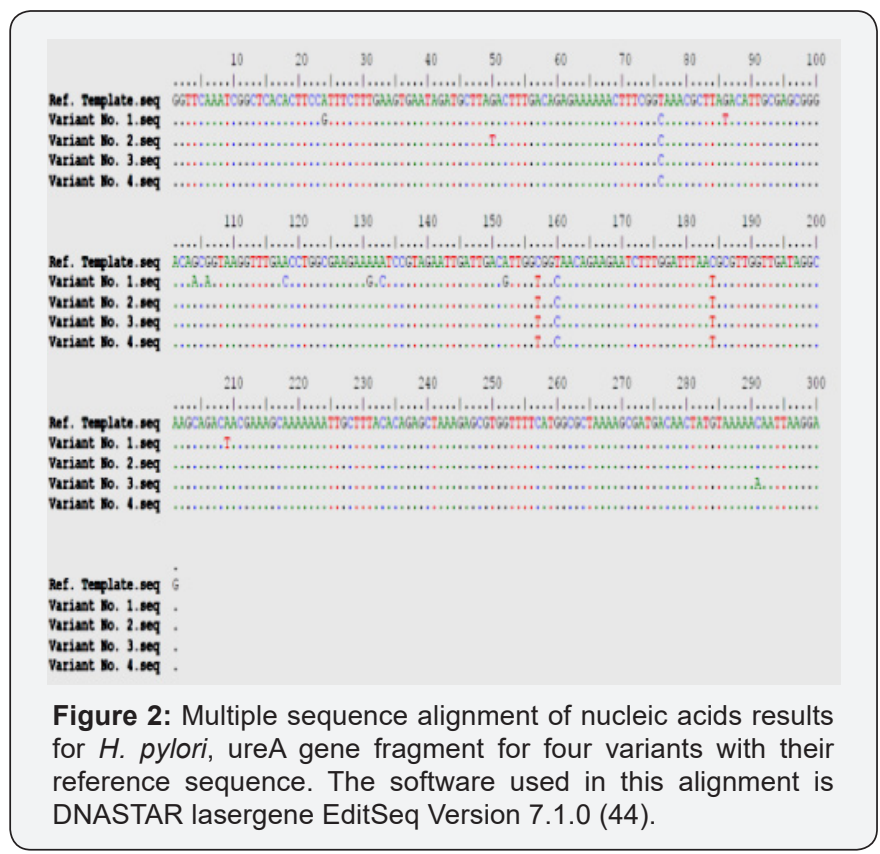

The polymorphisms of Helicobacter urease subunit alpha gene were detected by PCR / direct DNA sequencing method. Undoubtedly, too small sized of the studied groups is still 
a shortcoming of our research. Nonetheless, the observed sequencing variations nucleic acids indicate the detection of four different genetic variations with variable number of single nucleotide polymorphism [SNPs] (Figure 2). Sequencing results observed that variant No. 1 possesses very high SNPs variability compared with the reference as well as other variants nucleic acid sequences. The pattern and nature of each SNP that detected by sequencing may indicate that these SNPs are novel in their positions and consequences. The variant No. 1 has 13 SNPs (A 19 G, T 71 C, G 86 T, G 104 A, G 106 A, A 118 C, A 131 G, A 133 C, A 152 G, C 157 T, T 160 C, C 184 T, and A 209 T), and only four (T 71 C, C $157 \mathrm{~T}, \mathrm{~T} 160 \mathrm{C}$, and C $184 \mathrm{~T}$ ) are in common with other three variants (Table 1). The variant No. 2 has 5 SNPs (G 50 T, T 71 C, C 157 T, T 160 C, and C 184 T), and four (T 71 C, C 157 T, T 160 C, and $\mathrm{C} 184 \mathrm{~T}$ ) of them are in common with other three variants. The variant No. 3 has 5 SNPs (T 71 C, C 157 T, T 160 C, C 184 T, and C 291A), and four (T 71 C, C 157 T, T 160 C, and C 184 T) of them are in common with other three variants. The variant No. 4 has 4 SNPs (T 71 C, C 157 T, T 160 C, and C 184 T), and all of them are in common with other three variants, and no one unique SNP was identified.

Table 2: List of the correct reading frame of the studied urea PCR gene fragment that correspond the reading frame of the NCBI reference sequence. This frame is one of the six reading frame that deduced online using Expassy software for codons prediction.

\begin{tabular}{|c|c|}
\hline Ref. & Ref. Template Amino Acid Sequences \\
\hline & VQIGSHFHFFEVNRCLDFDREKTFGKRLDIASGTAVRFEPGEEKSVELIDIGGNRRIFGFNALVDRQADNESKKIALHRAKERGFHGAKSDDNYVKTIKE \\
\hline 1 & Variant No. 1 amino acid sequences \\
\hline & VQIGSHFRFFEVNRCLDFDREKTFGKRLYIASGTTVRFDPGEEDSVELIDVGGNRRIFGFNALVDRQADYESKKIALHRAKERGFHGAKSDDNYVKTIKE \\
\hline & Variant No. 2 amino acid sequences \\
\hline 3 & Variant No. 3 amino acid sequences \\
\hline & VQIGSHFHFFEVNRCLDFDREKTLGKRLDIASGTAVRFEPGEEKSVELIDIGGNRRIFGFNALVDRQADNESKKIALHRAKERGFHGAKSDDNYVKKIKE \\
\hline 4 & Variant No. 4 amino acid sequences \\
\hline & VQIGSHFHFFEVNRCLDFDREKTLGKRLDIASGTAVRFEPGEEKSVELIDIGGNRRIFGFNALVDRQADNESKKIALHRAKERGFHGAKSDDNYVKTIKE \\
\hline
\end{tabular}

Table 3: List of the number and positions of amino acids substitutions that obtained in each variant of ureA gene PCR fragment of $H$. pylori strains in comparison with their reference sequences. The software used in nucleic acids alignment is uniprotKB online software.

\begin{tabular}{|c|c|c|c|c|}
\hline No. & Variant No. 1 & Variant No. 2 & Variant No. 3 & Variant No. 4 \\
\hline 1 & H 8 R & $\ldots \ldots .$. & $\ldots \ldots \ldots$ & .......... \\
\hline 2 & ......... & D $17 \mathrm{Y}$ & $\ldots \ldots . .$. & $\ldots \ldots . .$. \\
\hline 3 & ......... & F $24 \mathrm{~L}$ & F $24 \mathrm{~L}$ & F $24 \mathrm{~L}$ \\
\hline 4 & D $29 \mathrm{Y}$ & …..... & $\ldots \ldots .$. & $\ldots \ldots .$. \\
\hline 5 & A $35 \mathrm{~T}$ & …..... & .......... & $\ldots \ldots .$. \\
\hline 6 & E $39 \mathrm{D}$ & ......... & ......... & $\ldots \ldots . .$. \\
\hline 7 & K $44 \mathrm{D}$ & ......... & ......... & ......... \\
\hline 8 & I $51 \mathrm{~V}$ & ......... & ......... & $\ldots \ldots .$. \\
\hline 9 & N $70 \mathrm{Y}$ & ......... & $\ldots \ldots .$. & $\ldots \ldots .$. \\
\hline 10 & $\ldots \ldots . .$. & ......... & Т $97 \mathrm{~K}$ & $\ldots \ldots \ldots$ \\
\hline
\end{tabular}

single nucleotide polymorphisms (SNPs) that obtained instions or of urea gene fragment of $H$. pylori strains in comparison with their reference sequences. The software used in nucleic acids alignment is DNASTAR lasergene EditSeq Version 7.1.0 (44).

\begin{tabular}{|c|c|c|c|c|}
\hline No. & Variant No. 1 & Variant No. 2 & Variant No. 3 & Variant No. 4 \\
\hline 1 & A 19 G & $\ldots \ldots \ldots .$. & ............ & $\ldots \ldots \ldots . .$. \\
\hline 2 & $\ldots \ldots \ldots$ & G $50 \mathrm{~T}$ & $\ldots \ldots \ldots$ & $\ldots \ldots \ldots . .$. \\
\hline 3 & $\mathrm{~T} 71 \mathrm{C}$ & $\mathrm{T} 71 \mathrm{C}$ & $\mathrm{T} 71 \mathrm{C}$ & $\mathrm{T} 71 \mathrm{C}$ \\
\hline 4 & G $86 \mathrm{~T}$ & $\ldots \ldots \ldots$ & $\ldots \ldots \ldots$. & $\ldots \ldots \ldots$. \\
\hline 5 & G $104 \mathrm{~A}$ & $\ldots \ldots \ldots .$. & $\ldots \ldots \ldots . .$. & $\ldots \ldots \ldots .$. \\
\hline 6 & G $106 \mathrm{~A}$ & $\ldots \ldots \ldots$. & ........... & .......... \\
\hline 7 & A 118 C & $\ldots \ldots \ldots$. & .......... & .......... \\
\hline 8 & A $131 \mathrm{G}$ & ........... & ............ & ........... \\
\hline 9 & A 133 C & $\ldots \ldots \ldots$. & $\ldots \ldots \ldots$. & ........... \\
\hline 10 & A $152 \mathrm{G}$ & $\ldots \ldots \ldots . .$. & $\ldots \ldots \ldots$ & ........... \\
\hline 11 & C $157 \mathrm{~T}$ & C $157 \mathrm{~T}$ & C $157 \mathrm{~T}$ & C $157 \mathrm{~T}$ \\
\hline 12 & T $160 \mathrm{C}$ & T $160 \mathrm{C}$ & T $160 \mathrm{C}$ & T $160 \mathrm{C}$ \\
\hline 13 & C $184 \mathrm{~T}$ & C $184 \mathrm{~T}$ & C $184 \mathrm{~T}$ & C $184 \mathrm{~T}$ \\
\hline 14 & A $209 \mathrm{~T}$ & $\ldots \ldots \ldots .$. & ............ & $\ldots \ldots \ldots .$. \\
\hline 15 & $\ldots \ldots \ldots .$. & ........... & C $291 \mathrm{~A}$ & ........... \\
\hline
\end{tabular}

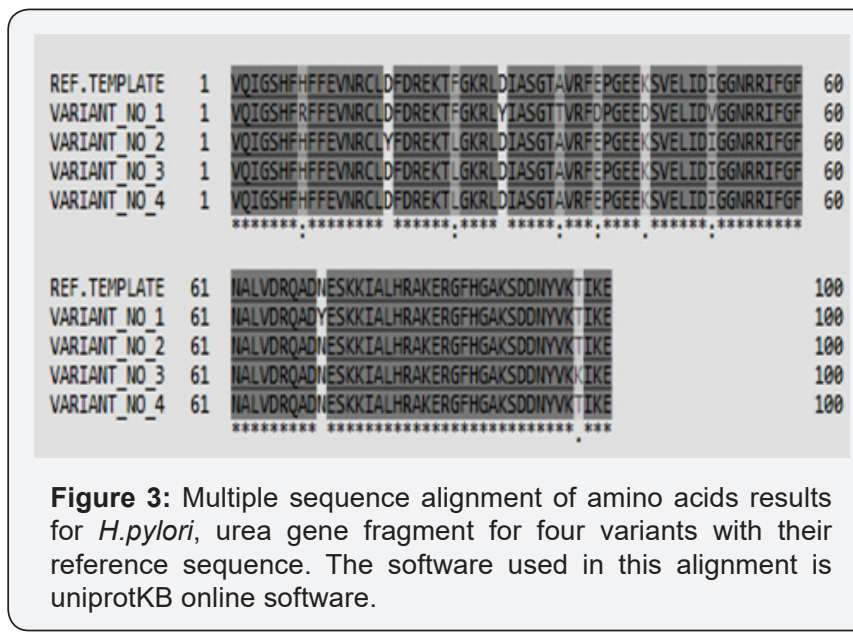

Since multiple reading frames can be extracted from each amino acid sequence, special software were used to predict the correct reading frame that suits the original reference reading frame in urease subunit alpha (Table 2). Once these suitable 
open reading frames were constructed, they compared with each other using uniprotKB software to see the final effect of the observed SNPs on the primary structure of proteins fragments Figure 3. Moreover, other data that found the high variability of urea gene isn't only stated in the levels of DNA, but it extends into the proteins' level too. According to Figure 3, it was found that variant No. 1 has seven amino acid changes (H 8 R, D 29 Y, A 35 T, E 39 D, K 44 D, I 51 V, and N 70 Y), and all of them aren't in common with the other three variants (Table 3). Variant No. 2 has two amino acids changes (D 17 Y, and F 24 L), and only one of them (F 24 L) is in common with the other three variants. Variant No. 3 has two amino acids changes (F 24 L, and T 97 K), and only one of them (F 24 L) is in common with the other three variants. Whereas variant No. 4 has only one amino acid change (F 24 L), which is in common with the other three variants. According to previously mentioned data, it was found that the variant No. 1 has distinct and significant variations in comparison and the reference, as well as other three amino acids sequences of the other three variants Figure 4. However, to get a complete idea about the extent and nature of these amino acid's changes, the whole sequence of urease subunit alpha was retrieved, and the accurate position of PCR products were localized. Table 4 . Hence, the real positions of these changes were relocalized Table 5 and introduced in the whole sequence of this protein. Accordingly, only ten amino acid changes were represented in all of these four observed variants Table 6 . Seven of non-synonymous mutations were represented in variant No. 1 (H 146 R, D 167 Y, A 173 T, E 177 D, K 182 D, I 189 V, and N 208 Y).

Table 4: The whole sequence of urease subunit alpha after its being retrieved from the NCBI website (accession number AY368265). The urease subunit alpha protein consists of 238 amino acids. The green highlighted STAT refers to start codon (methionine or M), while the red highlighted STOP refers to stop codon. The highlighted bold sequences represent the PCR products that constitute only 100 amino acids, which begin from $\mathrm{V}$ into $\mathrm{E}$.

\begin{tabular}{|c|c|c|}
\hline \multirow{3}{*}{ Start } & MKLTPKELDKLMLHYAGELAKKRKEKGIKLNYVEAVALISAHIMEEARAGK \\
& KTAAELMQEGRTLLKPDDVMDGVASMIHEVGFEAMFPDGTKLVT \\
& VHTPIEANGKLVPGELFLKNEDITINEGKKAVSVKVKNVGDRPVQIGS HFHFF \\
& EVNRCLDFDREKTFGKRLDIASGTAVRFEPGEEKSVELI DIGGNRRIFGFNALVDRQADNESKK \\
\hline
\end{tabular}

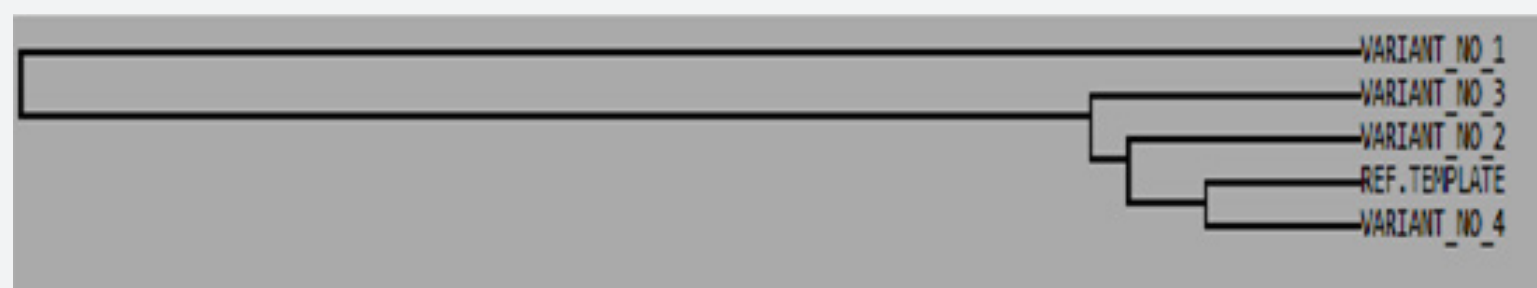

Figure 4: Internal phylogenic tree of multiple sequence alignment of amino acids results for $\mathrm{H}$. pylori, ureA gene fragment for four variants with their reference sequence. This alignment is made only between the reference sequences and its four variants that consists of only 100 amino acids out of 238 amino acids of the whole sequence of the protein. The software used in this alignment is uniprotKB online software.

Table 5: List of the real number and positions of amino acids substitutions that obtained in each variant of urease subunit alpha whole amino acid sequences of $H$. pylori strains in comparison with their reference sequences. The software used in nucleic acids alignment is uniprotKB online software.

\begin{tabular}{|c|c|c|c|c|}
\hline No. & Variant No. 1 & Variant No. 2 & Variant No. 3 & Variant No. 4 \\
\hline 1 & H 146 R & ......... & $\ldots \ldots .$. & $\ldots \ldots$. \\
\hline 2 & $\ldots \ldots .$. & D $155 \mathrm{Y}$ & $\ldots \ldots .$. & $\ldots \ldots .$. \\
\hline 3 & $\ldots \ldots .$. & F $162 \mathrm{~L}$ & F $162 \mathrm{~L}$ & F $162 \mathrm{~L}$ \\
\hline 4 & D $167 \mathrm{Y}$ & ......... & $\ldots \ldots \ldots$ & $\ldots \ldots \ldots$ \\
\hline 5 & A $173 \mathrm{~T}$ & ......... & ......... & ........ \\
\hline 6 & E 177D & $\ldots \ldots \ldots$ & $\ldots \ldots \ldots$ & $\ldots \ldots \ldots$ \\
\hline 7 & K 182 D & ......... & $\ldots \ldots$. & $\ldots \ldots \ldots$ \\
\hline 8 & I $189 \mathrm{~V}$ & ......... & $\ldots \ldots .$. & $\ldots \ldots .$. \\
\hline 9 & N 208 Y & ......... & $\ldots \ldots$. & $\ldots \ldots \ldots$ \\
\hline 10 & $\ldots \ldots .$. & $\ldots \ldots .$. & T $235 \mathrm{~K}$ & ......... \\
\hline
\end{tabular}

The non-synonym mutations that exist in variant No. 1 was shown seven amino acids changes. The conversions of histidine into argenine, lysine into aspartate, glutamate into aspartate, all polar charged amino acids, and isoleucine into valine, both hydrophobic aliphatic amino acids (in the positions 146, 177, 182, and 189 respectively), may not have a drastic effect on the protein structure since all of these converted amino acids residues have the same functional units Figure $5 \& 6$.

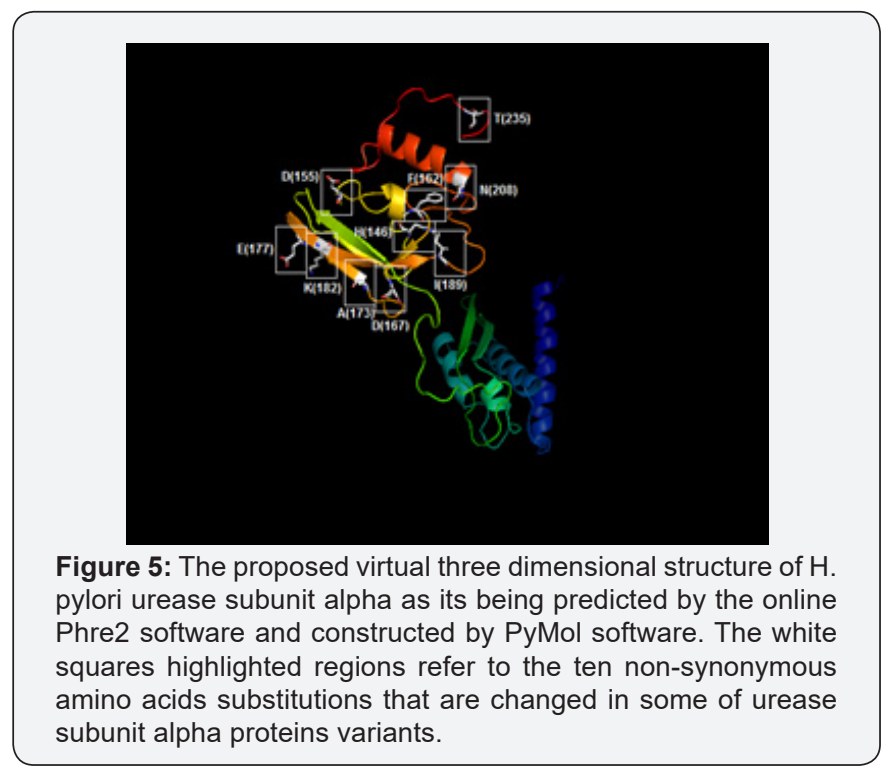




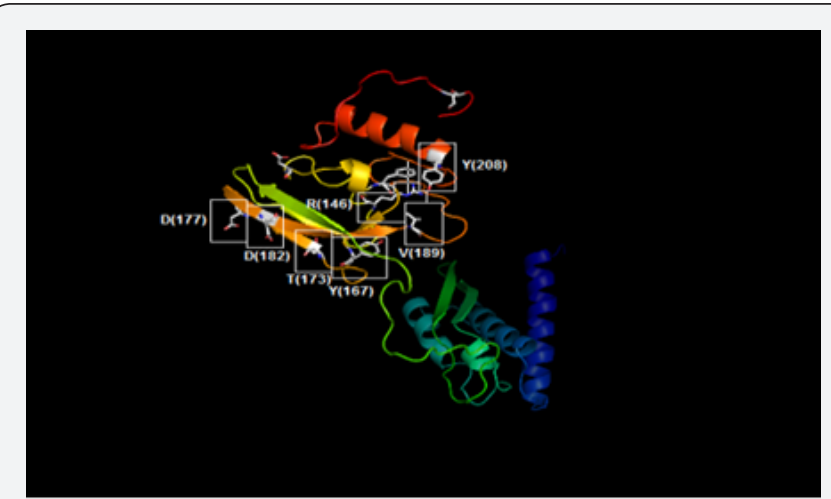

Figure 6: The virtual outcome for the changes of seven amino acids of reference urease subunit alpha protein into other amino acids counterparts in variant No. $1(H \rightarrow R / 146, D \rightarrow Y / 167$, $\mathrm{A} \rightarrow \mathrm{T} / 173, \mathrm{E} \rightarrow \mathrm{D} / 177, \mathrm{~K} \rightarrow \mathrm{D} / 182, \mathrm{I} \rightarrow \mathrm{V} / 189$, and $\mathrm{N} \rightarrow$ $\mathrm{Y} / 208)$. The tree dimensional structure is predicted by online Phre2 software and constructed by PyMol software.

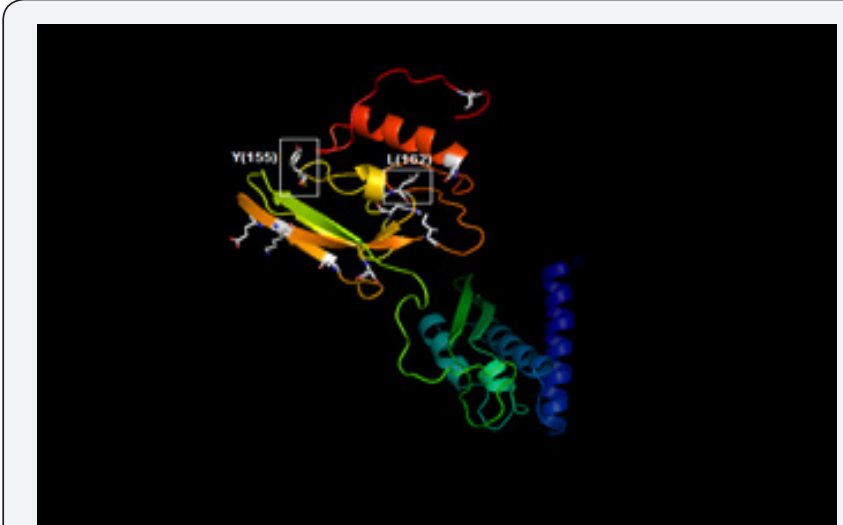

Figure 7: The virtual outcome for the changes of two amino acids of reference urease subunit alpha protein into other amino acids counterparts in variant No. $2(\mathrm{D} \rightarrow \mathrm{Y} / 155$, and $\mathrm{F} \rightarrow \mathrm{L} / 162)$. The tree dimensional structure is predicted by online Phre2 software and constructed by PyMol software.

Table 6: List of the number and types of nucleotides substitutions or SNPs that obtained in each variant of urea gene PCR fragment that included in the whole sequence urea gene of $H$. pylori strains in comparison with their reference sequences.

\begin{tabular}{|c|c|c|c|c|c|c|c|}
\hline No. & Variant No. 1 & Variant No. 2 & Variant No. 3 & Variant No. 4 & Codon No. & AA change & Type of SNP \\
\hline 1 & A 19 G & $\ldots \ldots \ldots$ & ............... & ............... & 146 & $\mathrm{H} \rightarrow \mathrm{R}$ & Non-synonymous \\
\hline 2 & $\ldots \ldots \ldots .$. & G $50 \mathrm{~T}$ & $\ldots \ldots \ldots$ & $\ldots \ldots \ldots$ & 155 & $\mathrm{D} \rightarrow \mathrm{Y}$ & Non-synonymous \\
\hline 3 & $\ldots \ldots \ldots$. & $\mathrm{T} 71 \mathrm{C}$ & $\mathrm{T} 71 \mathrm{C}$ & $\mathrm{T} 71 \mathrm{C}$ & 162 & $\mathrm{~F} \rightarrow \mathrm{L}$ & Non-synonymous \\
\hline 4 & G $86 \mathrm{~T}$ & .............. & .............. & .............. & 167 & $\mathrm{D} \rightarrow \mathrm{Y}$ & Non-synonymous \\
\hline 5 & G $104 \mathrm{~A}$ & $\ldots \ldots \ldots .$. & ........... & ........... & $\ldots \ldots \ldots .$. & ........... & Synonymous \\
\hline 6 & G $106 \mathrm{~A}$ & $\ldots \ldots \ldots . .$. & $\ldots \ldots \ldots . .$. & ............ & 173 & $\mathrm{~A} \rightarrow \mathrm{T}$ & Non-synonymous \\
\hline 7 & A $118 \mathrm{C}$ & $\ldots \ldots \ldots .$. & ........... & ........... & 177 & $\mathrm{E} \rightarrow \mathrm{D}$ & Non-synonymous \\
\hline 8 & A $131 \mathrm{G}$ & $\ldots \ldots \ldots$. & ........... & ........... & $\ldots \ldots \ldots .$. & ........... & Synonymous \\
\hline 9 & A 133 C & ............ & ............ & ............ & 182 & $\mathrm{~K} \rightarrow \mathrm{D}$ & Non-synonymous \\
\hline 10 & A 152 G & ............... & ............... & ............... & 189 & $\mathrm{I} \rightarrow \mathrm{V}$ & Non-synonymous \\
\hline 11 & C $157 \mathrm{~T}$ & $\mathrm{C} 157 \mathrm{~T}$ & C $157 \mathrm{~T}$ & C $157 \mathrm{~T}$ & ........... & ........... & Synonymous \\
\hline 12 & T $160 \mathrm{C}$ & T $160 \mathrm{C}$ & T $160 \mathrm{C}$ & T $160 \mathrm{C}$ & ........... & ........... & Synonymous \\
\hline 13 & $\mathrm{C} 184 \mathrm{~T}$ & C $184 \mathrm{~T}$ & C $184 \mathrm{~T}$ & $\mathrm{C} 184 \mathrm{~T}$ & $\ldots \ldots \ldots .$. & $\ldots \ldots \ldots$. & Synonymous \\
\hline 14 & A $209 \mathrm{~T}$ & $\ldots \ldots \ldots .$. & $\ldots \ldots \ldots .$. & $\ldots \ldots \ldots .$. & 208 & $\mathrm{~N} \rightarrow \mathrm{Y}$ & Non-synonymous \\
\hline 15 & $\ldots \ldots \ldots$ & $\ldots \ldots \ldots$ & C $291 \mathrm{~A}$ & ............. & 235 & $\mathrm{~T} \rightarrow \mathrm{K}$ & Non-synonymous \\
\hline
\end{tabular}

Whereas, the conversion of aspartic acid, the polar charged amino acid into tyrosine, the hydrophobic aromatic amino acid, alanine, the hydrophobic aliphatic amino acid into threonine, the polar uncharged amino acid, and asparagine, the polar uncharged amino acid, into tyrosine, the hydrophobic aromatic amino acid (in positions 167, 173, and 208 respectively) have potential drastic effect of on the final manifestation of the protein structure since all of these converted amino acids residues have different functional units Figure 6. The non-synonym mutations that exist in variant No. 2 was shown two amino acids changes. The conversions of aspartate, the polar charged amino acid into tyrosine, the hydrophobic aromatic amino acid, and the conversion of phenylalanine, the hydrophobic aromatic amino acid, into leucine, the hydrophobic aliphatic amino acid (in positions 155 and 162) may have dramatic effect on protein three-dimensional structure and function Figure 7.

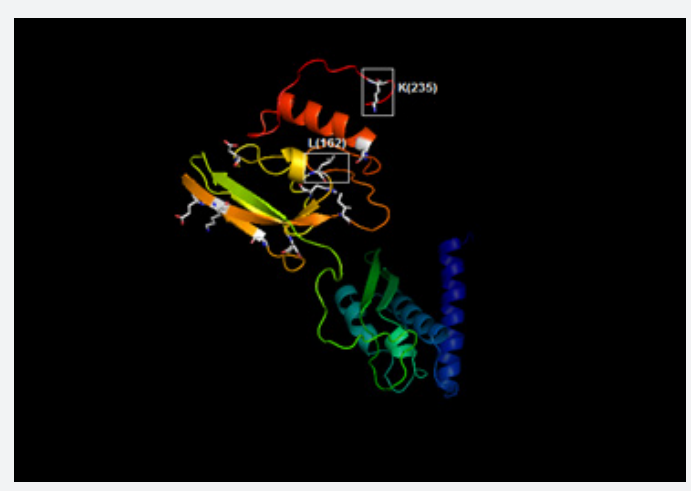

Figure 8: The virtual outcome for the changes of two amino acids of reference urease subunit alpha protein into other amino acids counterparts in variant No. $3(\mathrm{~F} \rightarrow \mathrm{L} / 162$, and $\mathrm{T} \rightarrow \mathrm{K} / 235)$. The tree dimensional structure is predicted by online Phre2 software and constructed by PyMol software. 
As well, the non-synonym mutations that exist in variant No. 3 was shown two amino acids changes. In addition to phenylalanine / leucine conversion that observed in variant No. 2 , another conversion was observed from threonine, the polar uncharged amino acid into lysine, the polar charged amino acid (in position 235) These two changes may have dramatic effect on the three-dimensional structure too Figure 8. In variant No. 4 , only one amino acid conversion was observed, which has been observed in both variant No. 2 and variant No. 3. Figure 9. It was obviously found in this study that variant No. 1 is genetically distinct from all other three observed variants as well as the reference sequences Figure 10. Thus, the variant No. 1 is highly polymorphic and may be regarded as a mutational hotspot, or the high variable site, leading to ligand diversity. The high genetic dissimilarity that we observed in this studied variant in comparison with its reference breed sequences might be due to several factors, such as the type, location, or other factors since the nature of polymorphisms were potentially highly dependable on several factors in the determination of its final genetic polymorphism.

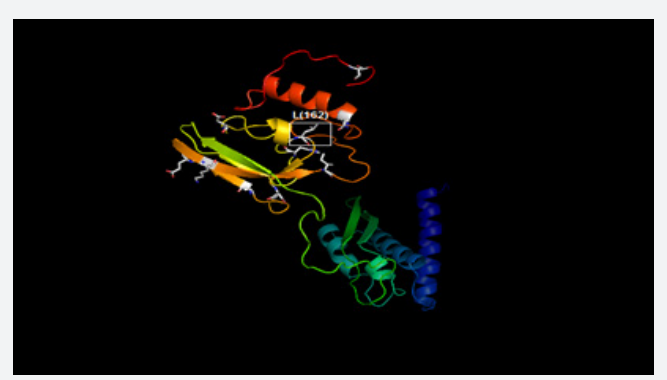

Figure 9: The virtual outcome for the changes of one amino acid of reference urease subunit alpha protein into another one in variant No. $4(\mathrm{~F} \rightarrow \mathrm{L} / 162)$. The tree dimensional structure is predicted by online Phre2 software and constructed by PyMol software.

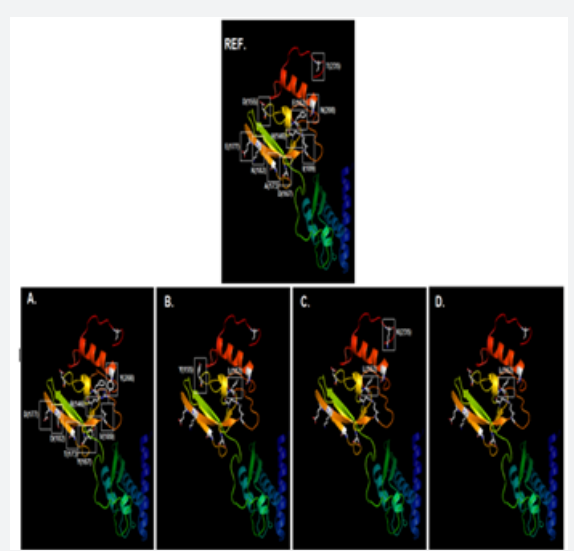

Figure 10: The virtual outcome for all changes of all amino acids of reference urease subunit alpha protein (ref.) into other amino acids counterparts in (A.) variant No. $1(\mathrm{H} \rightarrow \mathrm{R} / 146, \mathrm{~F} \rightarrow$ $\mathrm{L} / 162, \mathrm{D} \rightarrow \mathrm{Y} / 167, \mathrm{~A} \rightarrow \mathrm{T} / \mathrm{173}, \mathrm{K} \rightarrow \mathrm{D} / 182, \mathrm{I} \rightarrow \mathrm{V} / 189$, and $\mathrm{N} \rightarrow \mathrm{Y} / 208)$, (B.) variant No. $2(\mathrm{D} \rightarrow \mathrm{Y} / 155$, and $\mathrm{F} \rightarrow \mathrm{L} / 162)$, (C.) variant No. $3(\mathrm{~F} \rightarrow \mathrm{L} / 162$, and $\mathrm{T} \rightarrow \mathrm{K} / 235)$, and (D.) variant No. $4(\mathrm{~F} \rightarrow \mathrm{L} / 162)$. The tree dimensional structure is predicted by online Phre2 software and constructed by PyMol software.
In addition to the closeness of the amino acid's sequences of variants No. 2, 3, and 4, the phylogenetic tree that we construct has shown that the variant No. 1 has the most far genetic distance compared with the other observed three variants of this study as it was presented through several topological frames Figure 1113.
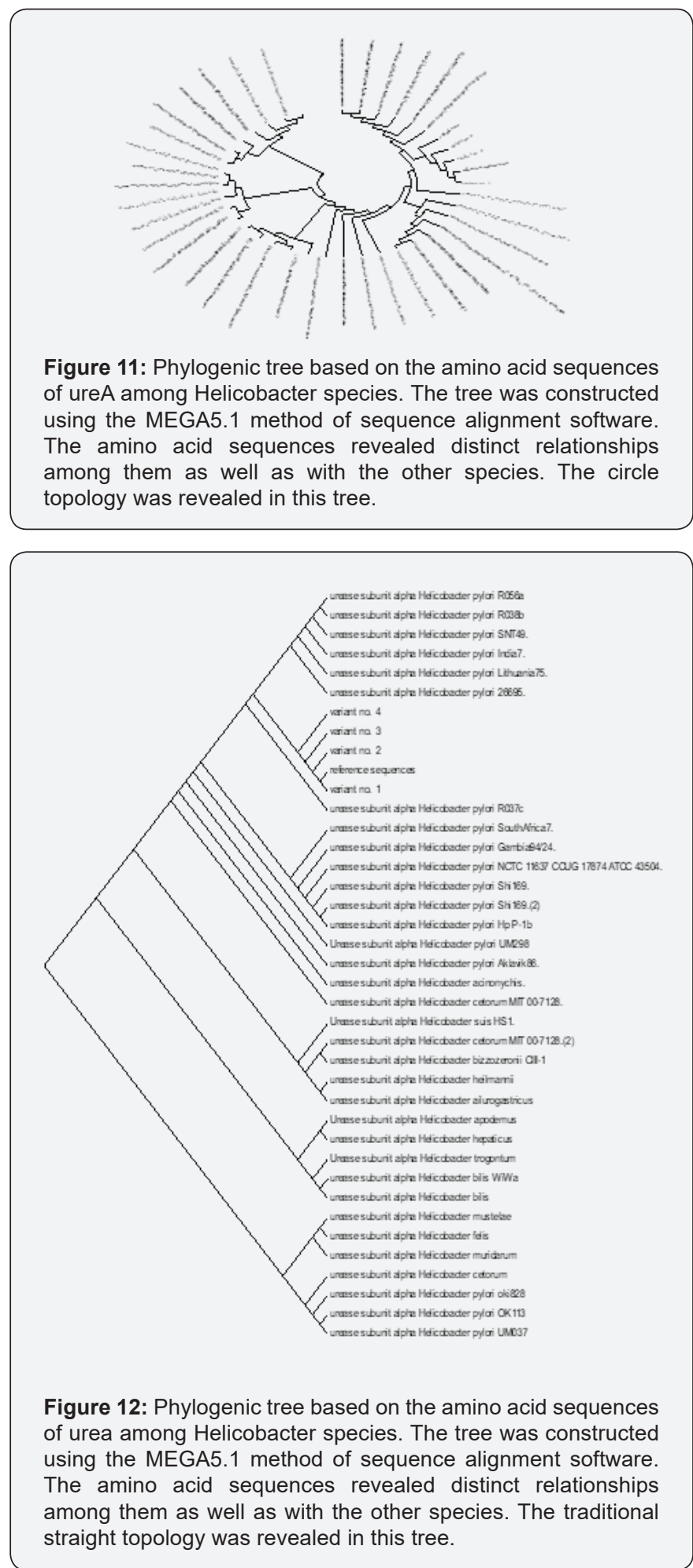

However, the observed variants of the current study are provided a beneficial tool for the geneticists and microbiologists 
to identify the unknown SNPs that may be useful for establishing a possible association with the genealogical relationships among these variations. The present study indicated that H.pylori isolated from patients with gastric cancer [variant 1] was highly polymorphic and was genetically distinct from H.pylori isolated from peptic ulcer [variants 2 and 3], and from patients with gastritis [variant 4]. These genetic diversity in our isolates was in line of previous studies performed in other geographical areas [8]. In addition, the variability was not confined to DNA only, but it extend to involve proteins and these variability may attribute to evolution of new H.pylori strains with high ability for gastric cancer induction. Cover [8], reported that there was presence of certain proteins in H.pylori with higher gastric cancer risk, which were absent in isolates with low gastric cancer risk. Thus genetic diversity and protein variability in H.pylori isolates may influence the incidence of gastric cancer and development of gastrointestinal diseases.

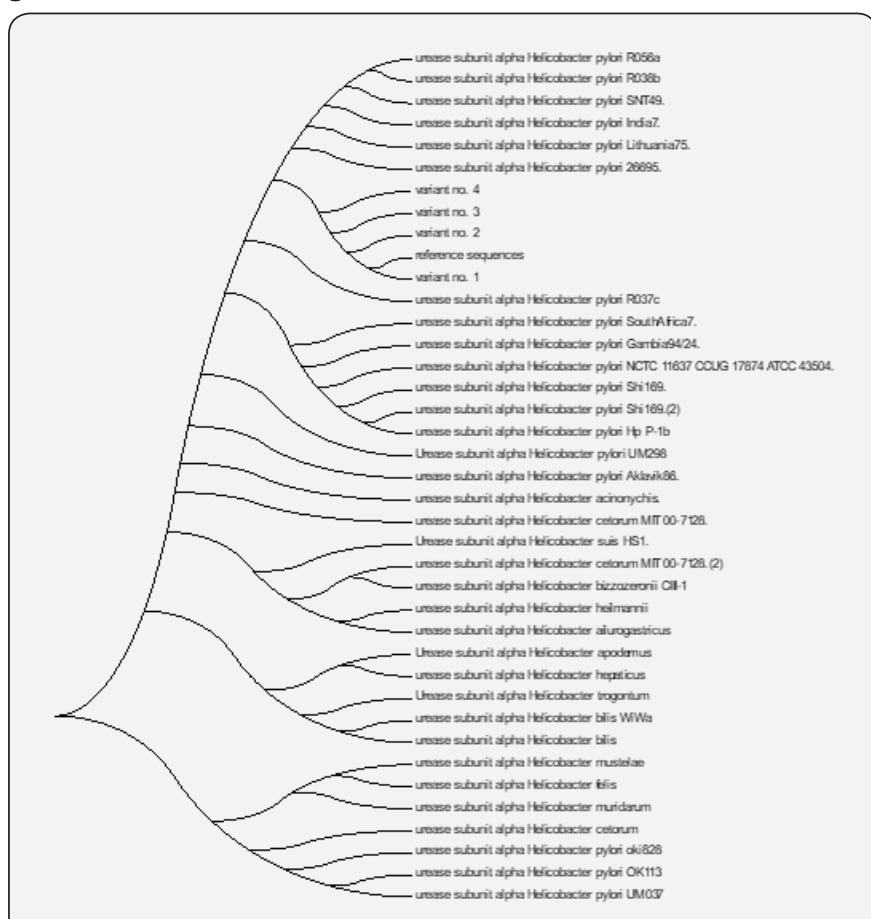

Figure 13: Phylogenic tree based on the amino acid sequences of ureA among Helicobacter species. The tree was constructed using the MEGA5.1 method of sequence alignment software. The amino acid sequences revealed distinct relationships among them as well as with the other species. The traditional curved topology was revealed in this tree.

The present study H.pylori isolates were separated on the phylogenetic tree and belong to a population cluster different from previously reported H.pylori sequences [9-12]. H.pylori variant 1 which was isolated from Iraqi patients with gastric cancer was most closely to strain Helicobacter pylori R037c isolated in Canada [11]. While variants 2 and 3, which were isolated from peptic ulcer and variant 4 , which was isolated from patient with gastritis were more closely to Helicobacter pylori 26695 isolated from patient with gastritis in UK [9]. The present study data suggest that sub lineages evolution within the Helicobacter pylori species may be associated with the development of less or more pathogenic potential. In addition, the relation of the 4 variants to the American [Hp R037c] and European [Hp 26695] suggest that these variants diverged from American and European lineage ancestors as reported previously for other geographical areas [11,13].

This study is the first one in Iraq that sequenced H.pylori isolates from patients with gastritis, peptic ulcer and gastric cancer and the gene diversity of the bacteria may be used as biomarker that may be used for follow up and prognosis in the above disease for prevention of development of cancer. Therefore, called GhaFa.1. Iraq for first isolate, GhaFa.2. Iraq for second isolate, GhaFa.3. Iraq for third isolate and GhaFa.4. Iraq for fourth isolate.

\section{Conclusion}

This study indicated that genetic variation in H. pylori was correlated to gastritis severity and was more in gastric cancer cases as compared to gastritis and peptic ulcer. This finding suggest that organism gene diversity influence the outcome and prognosis of $H$. pylori infections.

\section{Ethics Approval and Consent to Participate}

The research protocol was approved by Tikrit University College of Science Ethical Committee and informed consent was taken from each participant before their enrolment in the study.

\section{Consent for Publication}

All the authors were agreed for manuscript publication

\section{Authors Contributions}

All the authors were contributed in the study design, samples and data collection, investigational work, data analysis, and manuscript writing.

\section{References}

1. Testerman TL, Morris J (2014) Beyond the stomach: an update view of Helicobacter pylori pathogenesis, diagnosis and treatment. World J Gastroenterology 20(36): 12781-12808.

2. Alsamarai AGM, Thaegel F, Alobaidi AH (2017) Frequency of biomarkers positivity in Iraqi subjects with gastritis. Sci Int 5: 68-83.

3. Ahn HJ, Lee DS (2015) H. pylori in gastric carcinogenesis. World J Gastrointestinal Oncology 7(12): 455-465.

4. Sheh A, Lee CW, Masumura K, Rickman BH, Nohmi T, et al. (2010) Mutagenic potency of Helicopter pylori in the gastric mucosa of mice is determined by sex and duration of infection. Proc Natl Acad Sci USA 107(34): 15217-15222.

5. Alsamarai AGM, Moutar FT, Mohamed FI (2016) The significance of determination of pepsinogen A, pepsinogen C, gastrin, CD44 and interferon gamma in individuals with gastritis. WJPPS 5(7): 44-73.

6. Moutar FT, Alsamarai AGM, Mohamed FI (2016) Lipid profile in patients with gastritis. WJPPS 5(7): 74-90.

7. Gunaletchumy SP, Seevasant I, Tan MH, Croft LJ, Mitchell HM, et al. (2014) Helicobacter pylori Genetic Diversity and Gastro-duodenal Diseases in Malaysia. Sci Rep 4: 7431. 
8. Cover TL (2016) Helicobacter pylori diversity and gastric cancer risk. MBio 7(1): e01869-1815.

9. McClain MS, Shaffer CL, Israel DA, Peek RM Jr, Cover TL (2009) Genome sequence analysis of Helicopacter pylori strain associated with gastric ulceration and gastric cancer. BMC Genomics 10: 3 .

10. Duncan SS, Bertoli MT, Kersulyte D, Valk PL, Tamma S, et al. (2013) Genome sequences of three hpAfrica2 strains of Helicobacter pylori. Genome Announc 1(5): e729-813.

11. Blanchard TG, Zinn SJ, Correa P, Nakazawa T, Keelan M, et al. (2013) Genome sequences of 65 Helicobacter pylori strains isolated from asymptomatic individuals and patients with gastric cancer, peptic ulcer disease or gastritis 68(2): 39-43.

12. Rehvathy V, Tan MH, Gunaletchumy SP, Teh X, Wang S, et al. (2013) Multiple genome sequences of Helicobacter pylori strains of diverse disease and antibiotic resistance backgrounds from Malaysia. Genome Announc 1(5): e00687-713.

13. Kawai M, Furuta Y, Yahara K, Tsuru T, Oshima K, et al. (2011) Evolution in an oncogenic bacterial species with extreme genome plasticity: Helicobacter pylori East Asian genomes BMC microbiol 11: 104.

\section{Your next submission with JuniperPublishers will reach you the below assets}

- Quality Editorial service

- Swift Peer Review

- Reprints availability

- E-prints Service

- Manuscript Podcast for convenient understanding

- Global attainment for your research

- Manuscript accessibility in different formats

( Pdf, E-pub, Full Text, audio)

- Unceasing customer service

Track the below URL for one-step submission https://juniperpublishers.com/online-submission.php 